\title{
DETECÇÃO DE SOLOS ERODIDOS PELA AVALIAÇÃO DE DADOS ESPECTRAIS ${ }^{(1)}$
}

\author{
J . A. M. DE MATTÊ (2) \& D. FOCHT ${ }^{(3)}$
}

\begin{abstract}
RESUMO
O objetivo do presente trabalho foi avaliar a eficiência da reflectância espectral na discriminação e diagnóstico de diferentes níveis de erosão. Para tanto, quatro perfis de solos (Latossolo Vermelho-Amarelo, Terra Roxa Estruturada latossólica, Cambissolo de basalto e Vertissolo), localizados numa toposseqüência na região de Piracicaba, São Paulo, Brasil, foram submetidos à avaliação de atributos químicos, físicos e mineralógicos para verificar sua influência na reflectância. Os dados espectrais foram coletados, utilizando espectrorradiômetro no intervalo de 400 a $2.500 \mathrm{~nm}$, em laboratório. 0 processo erosivo dos solos foi considerado de acordo com as profundidades de coleta de amostras no perfil, sendo: 0-5, 10-20, 40-60 e 60-80 cm, correspondentes à erosão nula (testemunha), erosão ligeira, erosão moderada e erosão severa, respectivamente. Com os dados espectrais obtidos em laboratório, foram também simuladas respostas do TM-LANDSAT-5, relacionando-os com os atri butos do solo e os níveis de erosão. Na medida em que aumentou o grau de erosão, ocorreram alterações, princi palmente no teor de matéria orgânica, provocando modificações no caráter espectral. Quanto mais erodido foi o solo, maior a intensidade da curva espectral entre 600 e $2.400 \mathrm{~nm}$. As bandas de absorção devidas aos óxidos de ferro $(850 \mathrm{~nm})$, água $(1.400$ e $1.900 \mathrm{~nm})$ e caulinita $(2.200 \mathrm{~nm})$, por sua vez, apresentaram-se mais intensas nos solos erodidos. Os dados espectrais do LANDSAT mostraram-se menos detal hados e, por conseqüência, menos eficientes na detecção dos níveis de erosão. Apesar disso, as bandas 3, 4, 5 e 7 discriminaram os solos não erodidos dos erodidos por meio da intensidade e tendência das curvas.
\end{abstract}

Termos de indexação: sensoriamento remoto, erosão, radiometria.

\footnotetext{
(1) Recebido para publicação em dezembro de 1997 e aprovado em dezembro de 1998.

(2) Professor Doutor do Departamento de Solos e Nutrição de Plantas, Escola Superior de Agricultura "Luiz de Queiroz", ESALQ/ USP. Caixa Postal 9, CEP 13418-900 Piracicaba (SP). E-mail: jamdemat@carpa.ciagri.usp.br.

(3) Pós-Graduanda do curso de Solos e Nutrição de Plantas, ESALQ/USP. E-mail: dfocht@carpa.ciagri.usp.br
} 


\title{
SUMMARY: DETECTION OF SOIL EROSION BY SPECTRAL REFLECTANCE
}

\begin{abstract}
The objective of this work was to evaluate the efficiency of spectral reflectance in the detection of different erosion level s present in soil s. F our soils, corresponding to a Red-Y d low Latosol (Oxisol), Latosolic Terra Roxa Estruturada (Ultisol), Cambisol (Inceptisol) and Verti sol, located in a toposequencein Piracicaba, São Paul o, Brazil, wereeval uated for their chemical, physical and mineralogical attributes. The spectral reflectance was measured betwen 400 and 2,500 nm using an I nfra Red I nte ligent Spectroradi ometer. Each soil was coll lected according to the depth-increments $0-5,10-20,40-60,60-80 \mathrm{~cm}$, which wereconsidered as no erosion (control), slight erosion, moderate erosion and severe erosion, respectively. Spectral data obtained under laboratory conditions, which simulated data from the TMLANDSAT-5 satelite, were then correlated with the soil erosion process. As the degree of simulated erosi on increased, alterations in thesoils occurred, mainly with theorganic matter content, causing modifications in thespectral characteristics. Themore eroded thesoil, the higher was the spectral reflectance intensity between 600 and $2,400 \mathrm{~nm}$. The absorption bands, due to iron oxides $(850 \mathrm{~nm})$, water $(1,400$ and $1,900 \mathrm{~nm})$ and kaol inite $(2,200 \mathrm{~nm})$, were moreintensein theeroded soils. Spectral data from LANDSAT wereless detailed, for discriminating erosion levels in soils and, consequently, less efficient. Even under these conditions, bands 3, 4, 5 and 7 discriminated the non eroded soils from the eroded ones.

Index terms: remotesensing, soil erosion, radiometry.
\end{abstract}

\section{NTRODUÇÃO}

Boa parte da agricultura no Brasil desenvolvese mediante intensa pressão sobre os recursos naturais disponíveis, sendo o solo um dos mais afetados, decorrente do seu uso contínuo e, na maioria das vezes, de forma desmedida. Dos problemas causados por tal situação, a erosão tem sido o mais visível e um dos mais estudados, proporcionando informações sobre os montantes de terra perdidos nas mais diversas situações de manejo. Exemplo disto é o estado de São Paulo que perde por erosão 194 milhões de toneladas de terra por ano (Bertolini et al., 1993). Essas perdas de solo são uma conseqüência direta dos processos erosivos e causa de efeitos indiretos que agridem o ambiente.

Quando ocorre erosão em áreas agrícolas, o solo transportado carrega os el ementos nele presentes, provocando não só o assoreamento dos recursos hídricos existentes, mas também sua contaminação. Dessa forma, o potencial produtivo desses solos diminui, ocorrendo a necessidade de reposição dos elementos perdidos, el evando os custos de produção. Estima-se que, para produzir uma tonelada de soja, perdem-se por erosão 10 toneladas de terra, nos atuais sistemas de manejo, ou ainda, para produzir uma tonelada de milho, perdem-se 5 toneladas de terra (Lombardi Neto, 1997).

Baseado nestes aspectos, torna-se necessário o desenvolvimento de técnicas que auxiliem o diagnóstico de solos erodidos, para melhor monitoramento dos impactos ambientais.
O decréscimo da produtividade agrícola das terras devido aos processos erosivos, assim como sua recuperação, tem sido assunto de diversos trabal hos. Os métodos mais empregados para tais estudos foram resumi dos por Sparovek et al. (1991), a saber: (1) ensaios simulados em casa de vegetação; (2) medidas feitas diretamente no campo; (3) elaboração de modelos empíricos baseados nos atributos dos solos; (4) remoção artificial deterra ou erosão simulada. Empregando o último método, já usado por Lal (1976), é possível ter-se um bom controle sobre as fontes de variação externas, assim como o de extrapolar resultados com relativa segurança para condições de erosão por chuva natural. Em relação à quantidade de terra a ser removida, não há um critério determinado. Assim, é que em seu trabalho, Dedecek (1987) removeu camadas de solo entre 0-20 nas espessuras de 0, 2 , 5,10 e $20 \mathrm{~cm}$.

O sensoriamento remoto é uma alternativa auxiliar no estudo de solos. Sensores são utilizados em trabalhos que relacionam teores de matéria orgânica, argila e ferro, em amostras da superfície do solo, com sua radiância (Al-Abbas et al., 1972; Demattê, 1995; Vitorello\& Galvão, 1996).

$\mathrm{Na}$ década de setenta, Seubert et al. (1979) estudaram a erosão do solo por meio da observação de espectros de reflectância em laboratório. Concluíram que havia diferença espectral deum solo erodido para um não erodido. Trabalhando em Indiana, com o intuito de desenvolver técnicas multiespectrais no mapeamento de solos, Weismiller 
\& Kaminsky (1978) determinaram que imagens MSS-LANDSAT ofereciam potencial para o diagnóstico de áreas severamente erodidas.

Por outrolado, trabal hos utilizando sensores em laboratório (Stoner \& Baumgardner, 1981; E piphanio et al., 1992; Formaggio et al., 1996) revelaram que solos diferentes possuem características espectrais distintas. Da mesma forma, trabalhos de Mathews et al . (1973), Demattêet al . (1998), Vitorello\& Galvão (1996); Demattê \& Garcia (1999) indicaram a existência de relação entre as características físicas, químicas emineralógicas dos sol os e seus respectivos dados espectrais.

Com base nas observações de Stoner \& Baumgardner (1980), Pazar (1983) afirmou, depois de uma série de ensaios, que os critérios espectrais quantitativos poderiam ser utilizados para definir uma classificação de erosão.

Diante do potencial observado, Latz et al . (1984) retomaram os estudos relacionados com a er osão do solo. Utilizando amostras de três grupos distintos de Alfisols, dos Estados Unidos, verificaram haver diferenças espectrais entre níveis distintos de erosão simulada. Tais autores simularam, por meio de dados delaboratório, respostas para o sistema devarredura multiespectral (MSS) do satélite LANDSAT. Concluíram quea variação na quanti dade de matéria orgânica ea presença deóxidos de ferroforam os princi pais atributos de distinção entre os níveis de erosão que, por sua vez, refletiram-se no caráter espectral.

Bober \& MacBride (1996) verificaram a utilidade do uso de imagens como complemento de informações para determinar áreas degradadas pelo manejo inadequado dos solos. Palylyk et al. (1991) utilizaram imagens do TM-LANDSAT de dois anos sucessivos, para prever áreas vulneráveis à erosão. Tais trabalhos demonstraram a importância do entendimento dos dados espectrais como complemento na avaliação de áreas degradadas.

Portanto, utilizando espectrorradiômetro em laboratório na faixa espectral entre 400 e $2.500 \mathrm{~nm}$, os objetivos deste trabal ho foram: (a) determinar se a variação dos atributos do solo, simulando um processo erosivo, é detectada pela reflectância espectral, obtida em laboratório, entre 400 e $2.500 \mathrm{~nm}$; (b) utilizando os dados entre $400 \mathrm{e}$ $2.500 \mathrm{~nm}$, simular a resposta espectral do TM/ LANDSAT-5, verificando sua eficiência na detecção dos níveis simulados de erosão.

\section{MATE RIAL E MÉTODOS}

\section{Caracterização da área de estudo}

Os solos estudados localizam-se na Escola Superior de Agricultura "Luiz de Queiroz" no município de Piracicaba (SP). Eles ocorrem numa toposseqüência caracterizada por material retrabalhado da Formação Rio Claro, definido por Penteado (1969) e constituído predominantemente por depósitos arenosos e de cascalhos, assentado sobre a formação Corumbataí (Almeida et al., 1981).

Nas cotas inferiores da toposseqüência em estudo, existe afloramento de um depósito de diabásio intemperizado, interrompendo a continuidade da Formação Corumbataí, que mais abaixo aflora e se assenta sobrea F ormação I rati, cuja baseéo diabásio (Demattê \& Marconi, 1991).

A regiãoécaracterizada por um clima subtropical de inverno seco, em que a temperatura média do mês mais frio é inferior a $18^{\circ} \mathrm{C}$, e a do mais quente ultrapassa $22^{\circ} \mathrm{C}$. A precipitação média anual está em torno de $1.200 \mathrm{~mm}$, concentrada durante o verão (Brasil, 1960).

\section{Caracterização dos solos e obtenção das amostras}

Quatro perfis de solos localizados desde a parte alta até a parte baixa da toposseqüência foram caracterizados deacordo com Lemos \& Santos (1996). Os solos foram classificados como Latossolo Vermelho-Amarelo (LV), Terra Roxa Estruturada Iatossólica (TRI), Cambissolo (C) e Vertissolo (V), de acordo com Camargo et al. (1987). Conforme as características de textura, profundidade efetiva, pedregosidade, relevo e declividade, os sol os foram classificados de acordo com o risco de erosão (Quadro 1).

O LV ea TRI estão sendo cultivados com culturas anuais, enquanto o $\mathrm{V}$ com cana-de-açúcar. Por sua vez, o C, em razão da declividade acentuada e da pedregosidade, está reflorestado.

Simular o grau de erosão pela remoção artificial de camadas do solo permite um bom controle sobre as fontes de variação externas (Dedecek, 1987). Por isso foram col etadas amostras de terra em diversas profundidades da trincheira. Ao mesmo tempo, e de acordo com a camada de terra amostrada, as classes de erosão foram designadas como: profundidade 0-5 cm (erosão nula), 10-20 cm (erosão ligeira), 40-60 cm (erosãomoderada), 60-80 cm (erosãosevera).

Foram retiradas três amostras simples de cada face da trincheira nas mesmas profundidades já estabel ecidas e enviadas para análises granulométricas, químicas e radiométricas.

\section{Obtenção dos dados espectrais}

As amostras de sol o foram secas em estufa a $45^{\circ} \mathrm{C}$ por $24 \mathrm{~h}$, moídas e peneiradas em peneira de $2 \mathrm{~mm}$, para homogeneização. Posteriormente, as amostras foram acondicionadas em placas de petri de $9 \mathrm{~cm}$ de diâmetro por $1,5 \mathrm{~cm}$ de al tura e niveladas, para que a superfícieficasse o menos rugosa possível. O sensor utilizado foi o Infra Red Intelligent Spectroradiometer (IRIS), com resolução de $2 \mathrm{~nm}$ na faixa de 400 a $1.000 \mathrm{~nm}$ e $4 \mathrm{~nm}$ entre 1.000 e $2.500 \mathrm{~nm}$. A partir 
Quadro 1. Características gerais dos perfis amostrados e sua classificação

\begin{tabular}{|c|c|c|c|c|c|}
\hline Perfil & $\begin{array}{l}\text { Posição na } \\
\text { vertente }\end{array}$ & Dedividade & Drenagem & Classificação do solo & $\begin{array}{l}\text { Vulnerabilidade } \\
\text { à erosão(1) }\end{array}$ \\
\hline & & $\%$ & & & \\
\hline $\mathrm{P} 1$ & Topo & 4,17 & $\begin{array}{l}\text { Fortemente } \\
\text { drenado }\end{array}$ & $\begin{array}{l}\text { Latossolo Vermel ho-Amarelo distrófico A } \\
\text { moderado textura média (LV) }\end{array}$ & Médio \\
\hline $\mathrm{P} 2$ & $\begin{array}{l}\text { Meia encosta } \\
\text { superior }\end{array}$ & 3,12 & Bem drenado & $\begin{array}{l}\text { Terra Roxa Estruturada Latossólica } \\
\text { eutrófica A moderado textura muito } \\
\text { argilosa (TRI) }\end{array}$ & Baixo/médio \\
\hline P3 & $\begin{array}{l}\text { Meia encosta } \\
\text { inferior }\end{array}$ & 30,00 & $\begin{array}{l}\text { Moderadamente } \\
\text { drenado }\end{array}$ & $\begin{array}{l}\text { Cambissolo eutrófico A moder ado textura } \\
\text { argilosa substrato basalto (C) }\end{array}$ & Alto \\
\hline P4 & Sopé da encosta & 5,00 & $\begin{array}{l}\text { Imperfeitamente } \\
\text { drenado }\end{array}$ & $\begin{array}{l}\text { Vertissolo eutrófico A chernozêmico } \\
\text { textura argilosa (V) }\end{array}$ & Médio \\
\hline
\end{tabular}

dessa resolução, o sensor obtém aproximadamente 675 pontos (ou bandas) entre 400 e $2.500 \mathrm{~nm}$ para elaboração da curva espectral. A geometria para a aquisição dos dados de reflectância é observada na figura 1. Utilizou-se, como padrão de referência absoluta, uma placa com $100 \%$ de reflectância. A razão entre o fluxo radiante espectral refletido pela superfície de uma amostra e o fluxo radiante espectral refletido pelo material de referência, iluminado e visado nas mesmas condições que a superfície da amostra, gera o "fator de reflectância bidirecional espectral" (Nicodemus et al., 1977). F oram real izadas três medidas radiométricas por amostra de solo.

Os dados espectrais foram avaliados por meio das curvas médias espectrais entre 400 e $2.500 \mathrm{~nm}$. Também foram utilizados para gerar outros resultados, simulandoas bandas do sensor Thematic Mapper (TM) LANDSAT-5. Para tanto, foi calculada

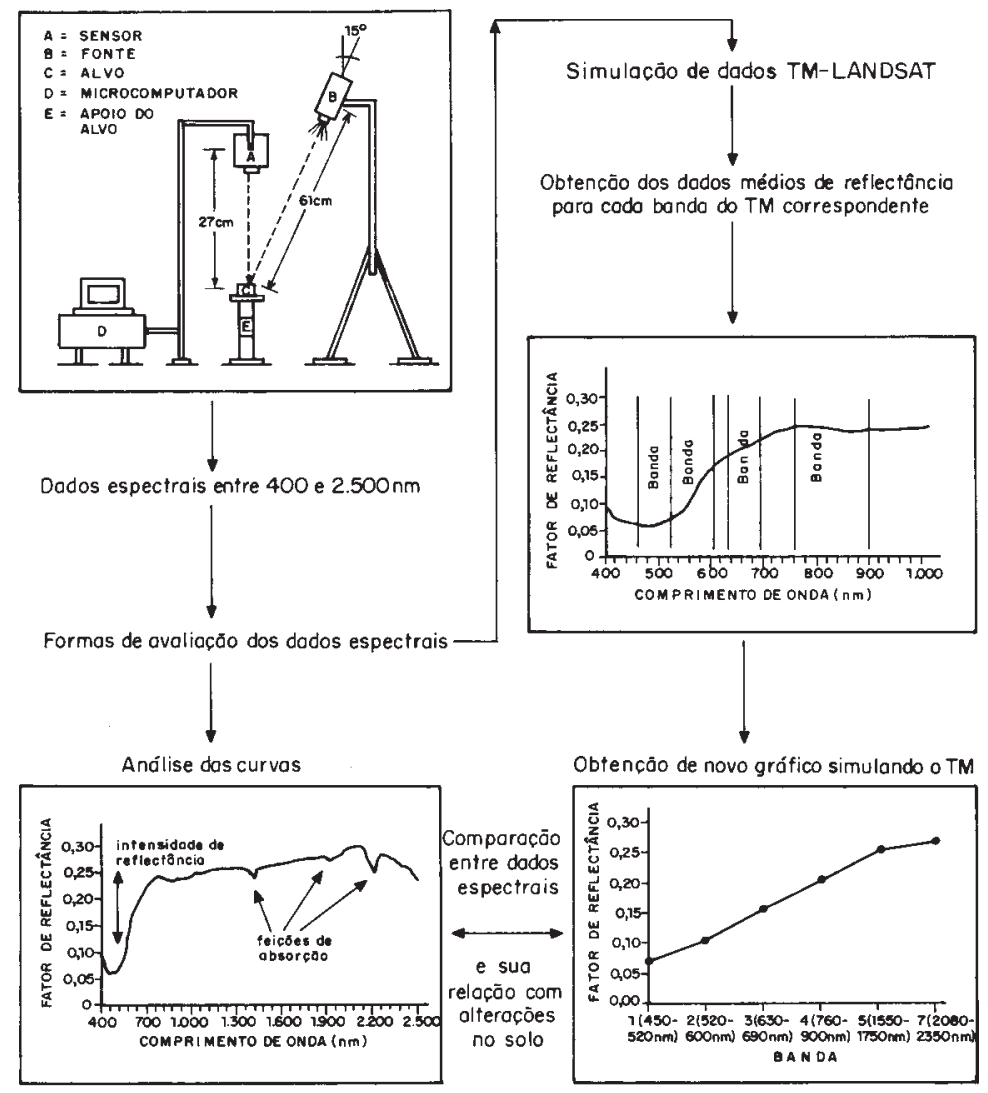

Figura 1. Fluxograma ilustrando a obtenção dos dados espectrais e sua avaliação. 
a média das respostas espectrais obtidas pel o sensor IRIS, nas faixas de comprimentos de onda correspondentes às bandas do TM-LANDSAT. São elas: 450-520, 520-600, 630-690, 760-900, 1.550-1.750, 2.080-2.350 nm, as quais correspondem, respectivamente, às bandas 1, 2, 3, 4, 5 e 7 (Figura 1).

As avaliações das curvas espectrais foram realizadas de acordo com as intensidades de reflectância das bandas e as feições de absorção e sua relação com os teores de ferro ematéria orgânica principalmente.

\section{Análises de solo}

Nas análises químicas, determinaram-se: $\mathrm{pH}$ $\left(\mathrm{CaCl}_{2}\right)$, teor de carbono orgânico, fósforo, potássio, magnésio, cálcio, alumínio e hidrogênio mais alumínio, segundo método descrito em Raij et al. (1987). F oram determinados teores de areia, silte e argila (Camargo et al., 1986). A sílica, a al umina e o ferro foram determinados após extração pel o ataque sulfúrico (Camargo et al., 1986). Para caracterizar os solos, realizaram-se análises mineralógicas da fração argila de acordo com J ackson (1969), as quais consistiram num pré-tratamento para elimi nação da matéria orgânica (água oxigenada a 30\%) e ferro livre (ditionito-citrato-bicarbonato desódio). A seguir, procedeu-se à separação granulométrica da fração areia (peneiração úmida), frações silte e argila (decantação). Amostras da fração argila foram saturadas por $\mathrm{K}+\mathrm{e}$ por $\mathrm{Mg}^{+2} \mathrm{e}$, posteriormente, transferidas para lâminas de vidro (esfregaço) e irradiadas por raios-X. As amostras de argila foram irradiadas num intervalo de 3 a 32 graus $2 \theta$. F oram obtidos difratogramas das amostras saturadas por $\mathrm{K}+\mathrm{a} 25^{\circ} \mathrm{C}, 350^{\circ} \mathrm{C}$ e $550^{\circ} \mathrm{C}$, e as saturadas por $\mathrm{Mg}+2 \mathrm{e}$ glicoladas.

\section{RESULTADOSE DISCUSSÃO}

\section{Erosão e atributos dos solos}

A erosão, simulada pelo procedimento de coleta de amostras de solo em diferentes profundidades, contribuiu para a diminuição da fertilidade. Em todos os perfis estudados, el ementos como o fósforo e, em muitos casos, também potássio, decresceram na medida em que a erosão do sol o tornou-se severa (Quadro 2). Essa constatação concorda com a afirmativa de Pandol fo (1994) que considera grandes as perdas de fósforo, provocadas pela erosão.

\section{Quadro 2. Valores médios ${ }^{(1)}$ das análises químicas dos solos}

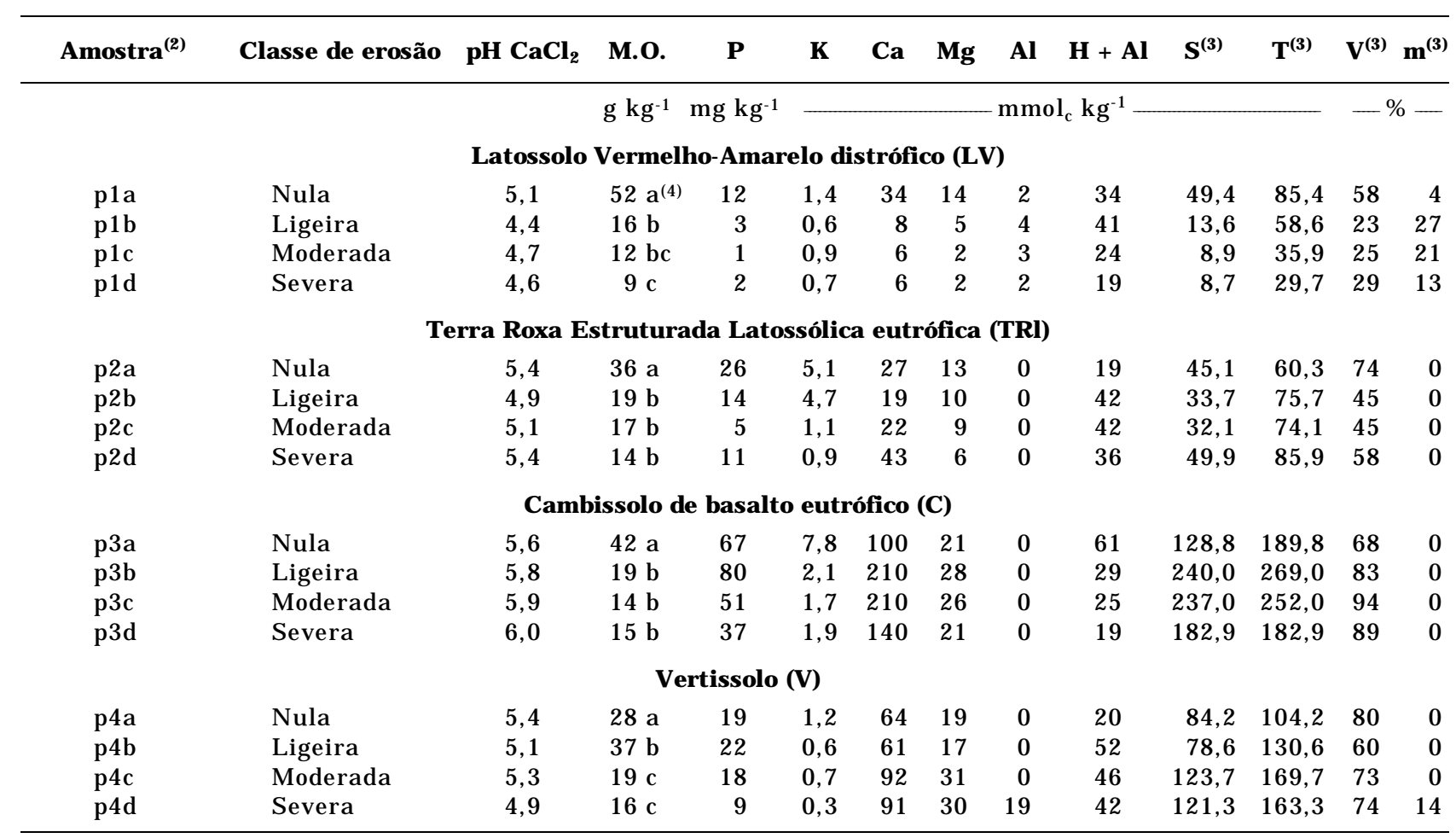

(1) M édia de três repetições. (2) p1 a p4: número do perfil; a, b, c, d, amostras de solos coletadas às profundidades de 0-5, 10-20, 40-60, 60-80 cm, referentes, respectivamente, aos níveis de erosão nula, ligeira, moderada e severa. (3) S: soma de bases; T: capacidade de troca de cátions; V: saturação por bases; m: saturação por alumínio. ${ }^{(4)}$ Resultados seguidos da mesma letra não diferem significativamente pelo teste $\mathbf{t}$ a $5 \%$. 
Comportamento semel hante pode ser observado nos teores de matéria orgânica apresentadas no quadro 2. Sparovek et al. (1993), trabalhando com erosão simulada, verificaram queum dos principais atributos no rendimento de plantas cultivadas foi a presença de matéria orgânica nas camadas superficiais. Neste contexto, o quadro 2 mostra que, dentro de uma classificação de erosão, onde vão sendo perdidas camadas de solo, ocorre grande decréscimo nas quantidades de matéria orgânica. Tal fato pode acarretar problemas no solo, como a menor retenção de água e nutrientes, menor agregação, dentre outros (Kiehl, 1985).

A análise física (Quadro 3) caracterizou os solos como de textura argil osa, com exceção do LV. Com esta característica, esses sol os são menos propensos a um processo de erosão natural, diante da resistência proporcionada pela presença de argila. Segundo Bertoni \& Lombardi Neto (1990), a distribuição quantitativa das classes detamanho de partículas que compõem o solo é de extrema importância na escol ha do uso e manejo dos solos.

Por outrolado, a posição no relevo e a declividade contribuem significativamente para o processo erosivo. Nesse caso, o Cambissolo (C) encontra-seno meio da encosta com declividade de 30\% (Quadro 1).
Aliado a isto, é um solo com drenagem moderada a imperfeita, tendendoa apresentar maior deflúvio do queinfiltração deágua (F rança \& Demattê, 1990), com conseqüente aumento da vulnerabilidade de erosão.

O Vertissolo (V), por sua vez, além de ser argiloso, encontra-senuma posição de relevo quase plano, com pequena declividade e, apesar da drenagem imperfeita, apresenta menor vulnerabilidadeà erosão.

\section{Curvas espectrais e erosão do solo}

As curvas espectrais do LV e TRI (Figura 2) mostram que as menores intensidades de reflectância estão associadas ao nível de erosão nulo, eocorreram entre 650 e $2.450 \mathrm{~nm}$, por apresentarem as amostras de erosão nula maior teor de matéria orgânica (Quadro 2) que absorve mais energia, diminuindo a reflectância entre 400 e 1.200 nm (Mathews et al., 1973) ou em todo o espectro óptico (Courault \& Girard, 1988; Madeira Netto, 1996). Para a erosão ligeira, há diminuição do teor de matéria orgânica (Quadro 2) produzindo aumento na intensidade de reflectância (Figura 2), o quetambém foi observado por Latz et al. (1984).

Para os níveis de erosão moderada e severa, a intensidade da curva entre 400 e 2.500 nm não se associa aos níveis de erosão, principal mente no caso

Quadro 3. Classe de erosão, cor do solo e valores médios ${ }^{(1)}$ das análises granulométricas, teor de $\mathrm{Fe}_{2} \mathrm{O}_{3}$ e Ki

\begin{tabular}{|c|c|c|c|c|c|c|c|}
\hline \multirow{2}{*}{ A mostra(2) } & \multirow{2}{*}{ Classe de erosão } & \multirow{2}{*}{ Cor úmida(3) } & \multicolumn{3}{|c|}{ Granulometria } & \multirow{2}{*}{$\mathrm{Fe}_{2} \mathrm{O}_{3}{ }^{(5)}$} & \multirow{2}{*}{$\mathbf{K} \mathbf{i}^{(\mathbf{6})}$} \\
\hline & & & Areia & Silte & Argila & & \\
\hline & & & \multicolumn{4}{|c|}{$\mathrm{g} \mathrm{kg}^{-1}$} & \\
\hline \multicolumn{8}{|c|}{ Latossolo Vermelho-Amarelo distrófico (LV) } \\
\hline $\begin{array}{l}\text { pla } \\
\text { p1b } \\
\text { plc } \\
\text { pld }\end{array}$ & $\begin{array}{l}\text { Nula } \\
\text { Ligeira } \\
\text { Moderada } \\
\text { Severa }\end{array}$ & $\begin{array}{l}7,5 Y R 3 / 2 \\
3 Y R 4 / 4 \\
5 Y R 4 / 5 \\
5 Y R 4 / 6\end{array}$ & $\begin{array}{l}660 \\
700 \\
630 \\
610\end{array}$ & $\begin{array}{r}100 \\
90 \\
80 \\
80\end{array}$ & $\begin{array}{l}240 \\
210 \\
290 \\
310\end{array}$ & $\begin{array}{l}39 a^{(7)} \\
32 a \\
41 a \\
44 a\end{array}$ & $\begin{array}{l}1,8 \\
1,9 \\
1,9 \\
1,8\end{array}$ \\
\hline \multicolumn{8}{|c|}{ Terra Roxa Estruturada Latossólica eutrófica (TRI) } \\
\hline $\begin{array}{l}\mathrm{p} 2 \mathrm{a} \\
\mathrm{p} 2 \mathrm{~b} \\
\mathrm{p} 2 \mathrm{c} \\
\mathrm{p} 2 \mathrm{~d}\end{array}$ & $\begin{array}{l}\text { Nula } \\
\text { Ligeira } \\
\text { Moderada } \\
\text { Severa }\end{array}$ & $\begin{array}{l}5 Y R 3 / 3 \\
2,5 Y R 2 / 4 \\
2,5 Y R 3 / 3 \\
2,5 Y R 3 / 3\end{array}$ & $\begin{array}{l}300 \\
270 \\
160 \\
170\end{array}$ & $\begin{array}{l}160 \\
170 \\
120 \\
100\end{array}$ & $\begin{array}{l}540 \\
560 \\
720 \\
730\end{array}$ & $\begin{array}{l}182 a \\
179 a \\
198 a \\
191 a\end{array}$ & $\begin{array}{l}1,5 \\
1,6 \\
1,7 \\
1,6\end{array}$ \\
\hline \multicolumn{8}{|c|}{ Cambissolo de basalto eutrófico (C) } \\
\hline $\begin{array}{l}\text { p3a } \\
\text { p3b } \\
\text { p3c } \\
\text { p3d }\end{array}$ & $\begin{array}{l}\text { Nula } \\
\text { Ligeira } \\
\text { Moderada } \\
\text { Severa }\end{array}$ & $\begin{array}{l}5 Y R 3 / 3 \\
2,5 Y R 2 / 4 \\
2,5 Y R 3 / 3 \\
2,5 Y R 3 / 3\end{array}$ & $\begin{array}{l}410 \\
330 \\
300 \\
290\end{array}$ & $\begin{array}{l}240 \\
230 \\
230 \\
230\end{array}$ & $\begin{array}{l}350 \\
440 \\
490 \\
480\end{array}$ & $\begin{array}{l}216 a \\
204 a \\
202 a \\
211 a\end{array}$ & $\begin{array}{l}2,3 \\
2,3 \\
2,2 \\
2,4\end{array}$ \\
\hline \multicolumn{8}{|c|}{ Vertissolo (V) } \\
\hline $\begin{array}{l}\mathrm{p} 4 \mathrm{a} \\
\mathrm{p} 4 \mathrm{~b} \\
\mathrm{p} 4 \mathrm{c} \\
\mathrm{p} 4 \mathrm{~d}\end{array}$ & $\begin{array}{l}\text { Nula } \\
\text { Ligeira } \\
\text { Moderada } \\
\text { Severa }\end{array}$ & $\begin{array}{l}7,5 Y R 3 / 0+7,5 Y R 4 / 4^{(4)} \\
2,5 Y R 4 / 0 \\
7,5 Y R 4 / 0+7,5 Y R 5 / 6^{(4)} \\
7,5 Y R+7,5 Y R 4 / 4^{(4)}\end{array}$ & $\begin{array}{l}360 \\
430 \\
370 \\
290\end{array}$ & $\begin{array}{l}260 \\
240 \\
190 \\
190\end{array}$ & $\begin{array}{l}380 \\
330 \\
440 \\
520\end{array}$ & $\begin{array}{r}243 a \\
114 b \\
68 c \\
86 c\end{array}$ & $\begin{array}{l}2,6 \\
2,8 \\
3,1 \\
3,0\end{array}$ \\
\hline
\end{tabular}

(1) Média de três repetições. ${ }^{(2)}$ pl a p4: número do perfil; a, b, c, d, amostras de sol os col etadas às profundidades de 0-5, 10-20, 40-60, 60-80 cm, referentes, respectivamente, aos níveis de erosão nula, ligeira, moderada e severa. (3) Munsell Color Charts, Baltimore,

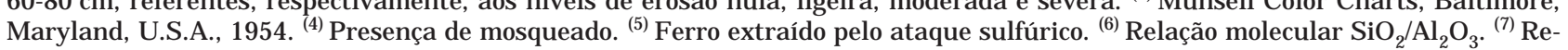
sultados seguidos da mesma letra não diferem significativamente pelo teste t a $5 \%$ de probabilidade. 


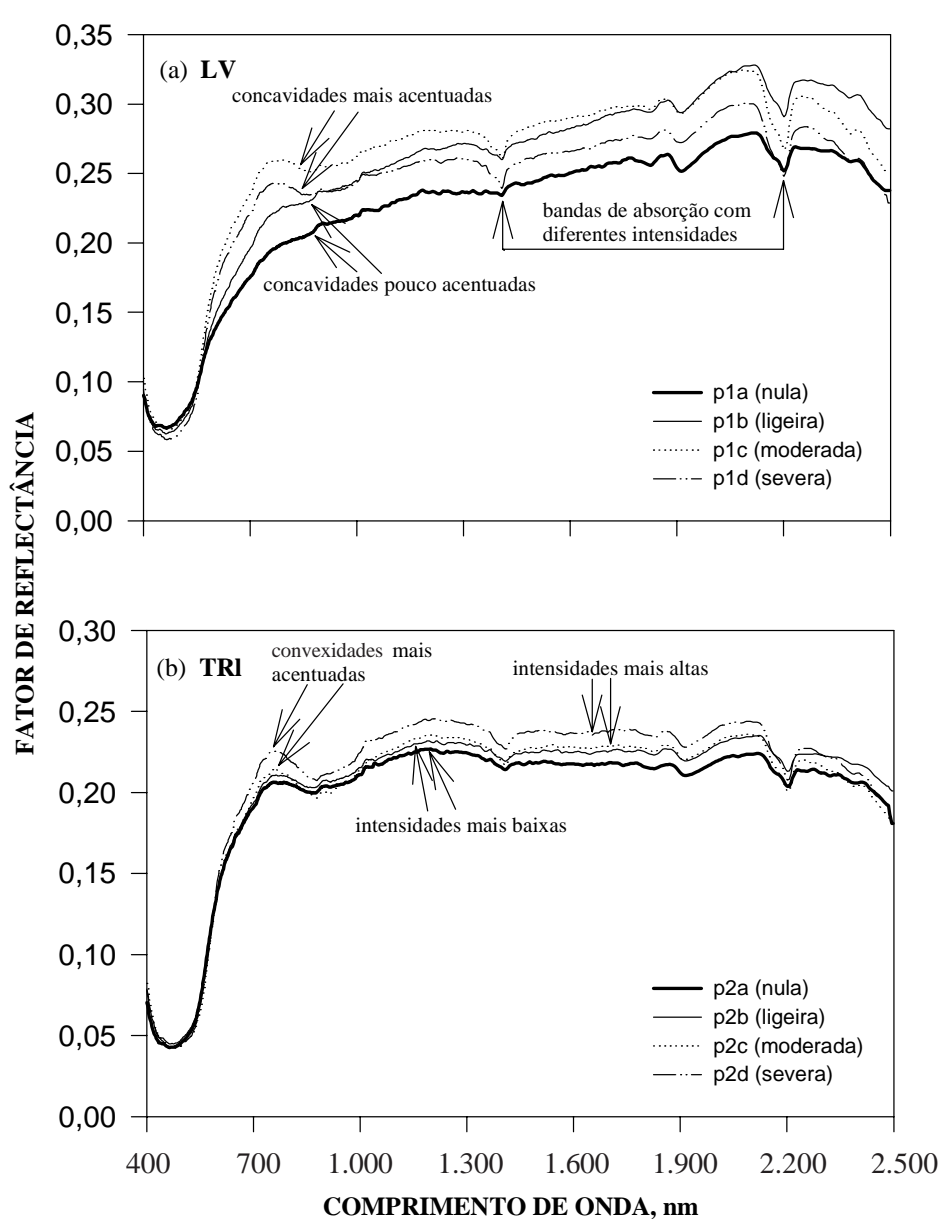

Figura 2. Dados espectrais obtidos com sensor terrestre do Latossolo Vermel ho-Amarelo LV (a) e Terra Roxa Estruturada Latossólica TR1 (b) designados por diferentes níveis de erosão.

do LV (Figura 2a), ou seja, entre os níveis de erosão ligeira, moderada e severa, não ocorreu a mesma seqüência de aumento da reflectância.

$\mathrm{Na}$ TRI, entre 700 e $2.150 \mathrm{~nm}$, observa-se que a intensidade de reflectância aumentou na mesma intensidade que a erosão (Figura 2b), concordando com resultados de Seubert et al. (1979) e de L atz et al. (1984).

No Cambissolo (C), a curva espectral mostra intensidade mais baixa, reflexo da presença de matéria orgânica em superfície que mascara o efeito dos óxidos deferro. E m contrapartida, à medida que as camadas mais superficiais são retiradas mediante a simulação da erosão, ocorre o aparecimento de uma concavidade mais forteentre 800 e $1.000 \mathrm{~nm}$ (Figura $3 a)$, evidenciando o efeito dos óxidos de ferro, como ocorreu com Latz et al. (1984).

No Vertissolo (V), apenas a erosão severa provocou uma reflectância maior, enquanto as demais curvas se confundem em termos de intensidade(Figura 3b).
As bandas em 1400 e 1.900 nm do LV (Figura 2a) são devidas às vibrações das moléculas de água presentes nos minerais deargila (Lindberg \& Snyder, 1972). Em 1.400 mm soma-sea influência dos grupos $\mathrm{OH}^{-}$, enquanto a banda em $2.200 \mathrm{~nm}$ (com formato característico) reflete a presença de caulinita (Mathews et al., 1973). O LV, com Ki na faixa de 1,9 (Quadro 3), apresentou a caulinita como um dos principais minerais de argila, conforme análise de raios-X (Figura 4a). A intensidade de absorção das bandas em 1.400 e $2.200 \mathrm{~nm}$ alterou-se na medida em que aumentaram os níveis de er osão. Neste caso, os dados apresentaram-se mais consistentes que para a intensidade da curva entre 400 e $2.500 \mathrm{~nm}$. Observou-se que, no LV , a banda em 1.400 e $2.200 \mathrm{~nm}$ é fraca para erosão nula, moderada para erosão ligeira e mais forte para a moderada e severa (Figura 2a). É provável que isto se deva à diminuição do teor de matéria orgânica que tem efeito de mascaramento sobre outros constituintes do solo e, por conseqüência, atenua a intensidade das bandas de absorção (Baumgardner et al., 1970). Da mesma 
forma, a redução de matéria orgânica permitiu sobressair o efeito dos óxidos de ferro na curva de reflectância. I sto podeser observado na figura 2a pela concavidade mais acentuada nos níveis de erosão moderada e severa, entre 750 e $1.000 \mathrm{~nm}$, a qual está associada aosóxidos deferro(Vitorello\& Galvão, 1996).

A mesma tendência foi observada para a TRI (Figura 2b). Verificou-se que os teores de ferro da TRI e do LV não se alteraram em profundidade, ao contrário da matéria orgânica (Quadros 2 e 3), mostrando que, apesar de o teor de ferro total não sealterar para a erosão nula e severa, a concavidade é diferente entre 750 e 1.000 nm, devida a influência da matéria orgânica. Segundo Latz et al. (1984), a influência dos óxidos de ferro em profundidade ocasiona um aumentona convexidade da curva entre 500 e $800 \mathrm{~nm}$, seguida de uma concavidade entre 800 e $1.000 \mathrm{~nm}$. Ao mesmo tempo, a presença de óxidos de ferro em profundidade promove a concavidade na curva espectral em $850 \mathrm{~nm}$ (Vitorello \& Galvão, 1996).

A TRI apresentou valores de $\mathrm{Ki}$ de 1,6, menor que o LV, bem como teores de ferro entre quatro a cinco vezes mais elevados (Quadro 3). Este solo é caracterizado por apresentar mais óxidos de ferro, o que explica a concavidade mais forte entre 700 e 1.000 nm (Figura 2) em relação ao LV, concordando com Vitorello \& Galvão (1996). Além disso, a análise mineralógica indicou a presença de caulinita, o que ér refletido na curva espectral pela banda a $2.200 \mathrm{~nm}$. Por outrolado, este sol o também apresentou gi bbsita, caracterizado pelos picos em 0,47 e 0,42 nm com tratamento $\mathrm{K} 25^{\circ} \mathrm{C}$ (Figura 4b) e colapso desses picos com aquecimento a $550^{\circ} \mathrm{C}$. A presença de gibbsita na curva espectral écaracterizada pela banda deabsorção em $2.265 \mathrm{~nm}$ (Madeira N etto, 1996). Entretanto, os resultados mostraram haver banda de absorção em $2.265 \mathrm{~nm}$, muito tênue (Figura 2a), indicando pequena contribuição desse óxido de alumínio.

O Cambissolo apresentou valores de $\mathrm{Ki}$ de 2,2 a 2,4 (Quadro 3), caracterizando-se como o sol o menos intemperizado que os anteriores. Este solo apresentou minerais 2:1 como a vermiculita, caracterizada pelos picos na faixa de $1,4 \mathrm{~nm}$ para tratamentos $\mathrm{K} 25^{\circ} \mathrm{C}$, e $\mathrm{Mg}$ glicolado e $1,0 \mathrm{~nm}$ com aquecimento a $550^{\circ} \mathrm{C}$ (Figura 4C). A caulinita

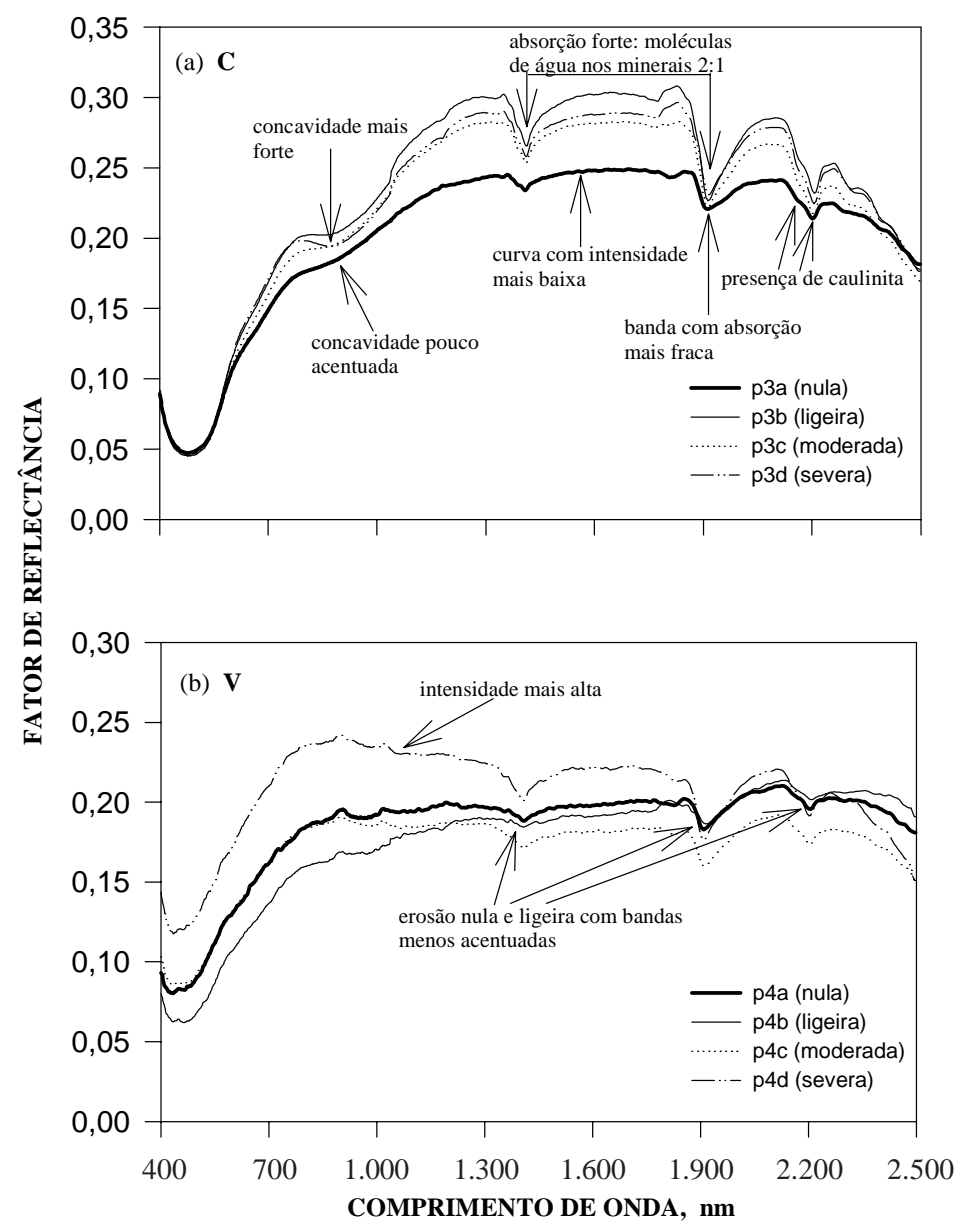

Figura 3. Dados espectrais obtidos com sensor terrestre do Cambissolo C (a) e Vertissolo V (b) desi gnados por diferentes níveis de erosão. 
também foi observada como um mineral importante neste solo. Estas características mineralógicas refletiram-se na curva espectral, conforme se observa na banda a $2.200 \mathrm{~nm}$ relacionada com os grupos $\mathrm{OH}$ da caulinita (Mathews et al., 1973). A banda em $1.400 \mathrm{~nm}$ é devida aos grupos OH eàs vibrações das moléculas deágua, enquanto em $1.900 \mathrm{~nm}$ é devida à água (Lindberg \& Snyder, 1972). Demattê et al. (1998), por sua vez, observaram que a curva da montmorilonita apresentou forte absorção em $1.900 \mathrm{~nm}$ diferenciando-se da caulinita. Por sinal, a vermiculita, mineral 2:1, também promove forte banda de absorção em $1.900 \mathrm{~nm}$ (Grove et al., 1992), como ocorrida nas curvas do $\mathrm{C}$ e detectada nas análises de raios- $X$.

No caso do $C$, a intensidade da curva espectral entre 600 e $2.400 \mathrm{~nm}$ foi menor para erosão nula e maior nas demais (Figura 3a). A avaliação da intensidade das feições de absorção também evidenciou diferenças entre a erosão nula e as demais. Porém, entre os níveis ligeiro a severo, a intensidade da curva entre 600 e 2.500 nm não se relacionou. O mesmo ocorreu quando se analisou a intensidade das bandas de absorção em 1.400, 1.900 e $2.200 \mathrm{~nm}$. Por outrolado, a forma da curva na faixa espectral entre 750 e $1.000 \mathrm{~nm}$, relacionada com os óxidos de ferro (Vitorello \& Galvão, 1996), modificouse (Figura 3a). A concavidade é pouco acentuada para erosão nula e ligeira e mais forte para erosão severa. Isto pode ter ocorrido por causa da diminuição da matéria orgânica de $42 \mathrm{~g} \mathrm{~kg}^{-1}$ na superfície para $15 \mathrm{~g} \mathrm{~kg}^{-1}$ na última camada (Quadro 2), permitindo sobressair o efeito dos óxidos de ferro presentes no solo.
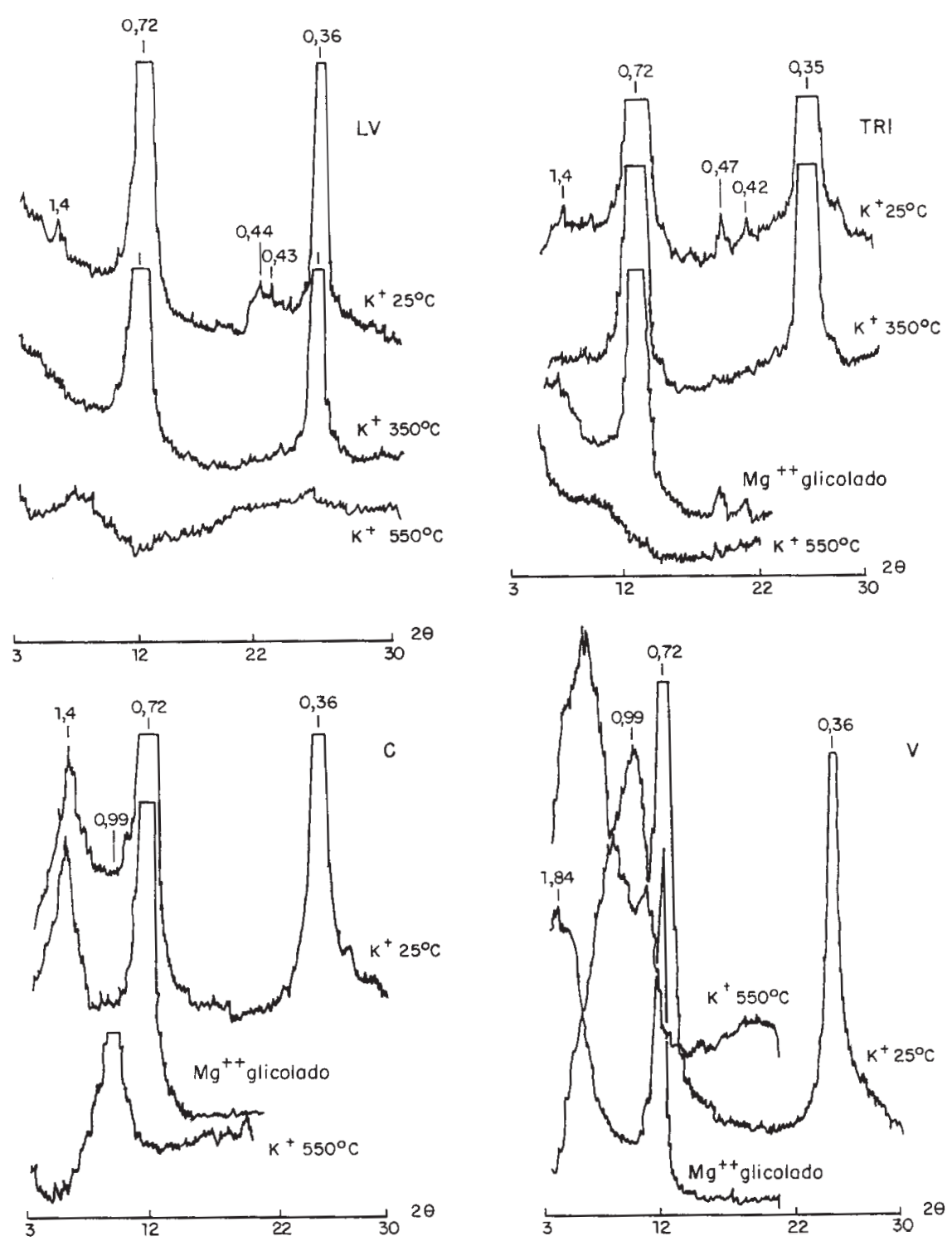

Figura 4. Difratogramas de raios-X da fração argila desferrificada: (a) LV-amostra plc; (b) TRI-amostra p2c; (c) C-amostra p3b; (d) V-amostra p3c (valores de d em nanômetros). 
As observações relativas às intensidades das bandas de absorção concordam com Stoner \& Baumgardner (1981). Tais autores verificaram que as duas principais características atuantes na resposta espectral dos solos são os conteúdos de matéria orgânica e ferro. Enquanto a matéria orgânica encontra-se em maior quantidade na superfície dos solos, mascarando a presença dos óxidos de ferro, estes têm sido determinados mais facilmente nas curvas espectrais quando em profundidade, onde a presença de matéria orgânica émenor. Assim, de acordo com as quantidades desses elementos no solo, as curvas espectrais resultantes terão bandas de absorção e intensidades distintas. As afirmações desses autores com rel ação à di ferença da intensi dade nas curvas espectrais são visíveis nas respostas obtidas. As curvas que correspondem ao nível nulo de erosão (que possuem maior quantidade de matéria orgânica) têm intensidade mais baixa do que as de nível severo, ondea expressão dos óxidos de ferroépredominante. Nestecaso, torna-seimportante a obtenção de dados espectrais quantitativos como informações auxiliares na definição e diagnóstico de classes de erosão, concordando com Pazar (1983).

No Vertissolo (Figura 3b), a avaliação da intensi dade das bandas de absorção em 1.400, 1.900 e $2.200 \mathrm{~nm}$ também se mostrou mais eficiente na discriminação dos níveis de erosão, ao contrário da intensidade da curva entre 400 e $2.500 \mathrm{~nm}$. Observou-se um aumento gradativo da intensidade de absorção dessas bandas de acor do com o aumento do nível de erosão.

O Vertissol o é um sol o pouco intemperizado com Ki na faixa de 2,6 a 3,0 (Quadro 3). Esse solo apresentou como minerais deargila predominantes a esmectita ea caulinita (Figura 4d). À semel hança do ocorrido nas curvas do $C$, as curvas do $\mathrm{V}$ apresentaram uma banda de absorção forte em $1.900 \mathrm{~nm}$ (Figura 3b). Tudo indica que essa banda seja devida à absorção proporcionada pelas vibrações das moléculas de água, principal mente nos minerais 2:1 (esmectita), concordando com observações de Demattê et al. (1998).

No Vertissolo, apesar de apresentar teor deferro total na faixa de $114 \mathrm{~g} \mathrm{~kg}^{-1}$, a concavidadeem $850 \mathrm{~nm}$ não ocorreu. Considerando que a concavidade em $850 \mathrm{~nm}$ é devida à presença dos óxidos de ferro cristalinos, hematita e goethita (Vitorello \& Galvão, 1996), eque, sendo oV um solojovem e pouco intemperizado, provavelmente as diferenças de intensidade sejam devidas ao ferro com baixo grau de cristalinidade. Tal observação concorda com os de Demattê \& L eite (1998) e Demattê \& Garcia (1999) que observaram que o ferro com baixo grau de cristalinidade altera a intensidade da curva espectral, mas não sua concavidade.

\section{Dados simulados do TM-LANDSAT e erosão do solo}

Os dados simulados do sensor IRIS nas mesmas faixas de reflectância das bandas do sensor Thematic
Mapper do LANDSAT-5, nestetrabalho, permitiram obter gráficos espectrais com um máximo de seis pontos, cada qual referente a uma banda. Nessa situação, observou-se nítida perda de detalhes do caráter espectral dos solos (Figuras 5 e 6), quando comparado com as curvas obtidas com sensor terrestre que obteve 675 pontos ou bandas para elaboração da curva espectral. I sto ocorreu pela forma que os dados do sensor terrestre foram manipulados (médias aritméticas das faixas correspondentes às bandas) para simular o TM LANDSAT, tendo as curvas obtidas com os 675 pontos demonstrado um nível de detal hamento muito maior.

Dada a ausência de visualização das bandas de absorção e formato das curvas espectrais, a aval iação tem de ser realizada por meio da intensidade de reflectância.

Observando a intensidade das bandas individualmente, verificou-se que, para o LV, TRI e $C$, as bandas 1 e 2 não discriminaram as áreas erodidas, enquanto no $\mathrm{V}$ sim (Figuras 5 e 6). A faixa espectral devida a estas bandas émuito influenciada pela matéria orgânica e óxidos de ferro. Pelo quadro 2, a matéria orgânica variou da camada superficial para a subsuperficial em todos os solos. Em contrapartida, o teor de ferro (Quadro 3) foi homogêneo em todos os solos, mas diminuiu significativamenteem profundidade noV, alterando as intensidades de reflectância.

Para oLV (Figura 5a), as bandas 3 e 4 mostraram aumento da intensidade da reflectância à medida que a erosão vai de nula para ligeira. Por outrolado, nas bandas 5 e 7, a erosão ligeira inverte e passa a ter maior intensidade que a severa, concordando com Latz et al. (1984). Na TRI, as diferenças ocorreram principalmente entre a erosão nula e a severa na banda 5 (Figura $5 b$ ).

Para o caso do C (Figura 6a), as bandas 3, 4, 5 e 7 discriminaram a erosão nula das demais. NoV, por sua vez, a curva da erosão ligeira está com menor reflectância que a erosão nula, o que se explica pelo maior teor de matéria orgânica ocorrente nas amostras (Quadro 2).

Os gráficos lineares mostraram uma tendência ascendente das bandas 1 para a 3, com decréscimo na inclinação entre as bandas 3 e 4, como ocorreu no trabal ho de Latz et al. (1984). Segundo esse mesmo autor, como a severidade da erosão é mais bem detectada na faixa entre 750 e 950 nm, a inclinação na resposta espectral decresce nesta faixa. Isto ocorre devido ao decréscimo do conteúdo de matéria orgânica em profundidade e melhor expressão dos óxi dos de ferro detectados quando há erosão severa. Para os sol os LV, TRI eV, observou-se que as curvas espectrais dos níveis de erosão nula e ligeira (Figuras 5 e 6) apresentaram tendência ascendente. I sto pode ser explicado pela tendência da intensi dade de reflectância entre as bandas 5 e 7 , 


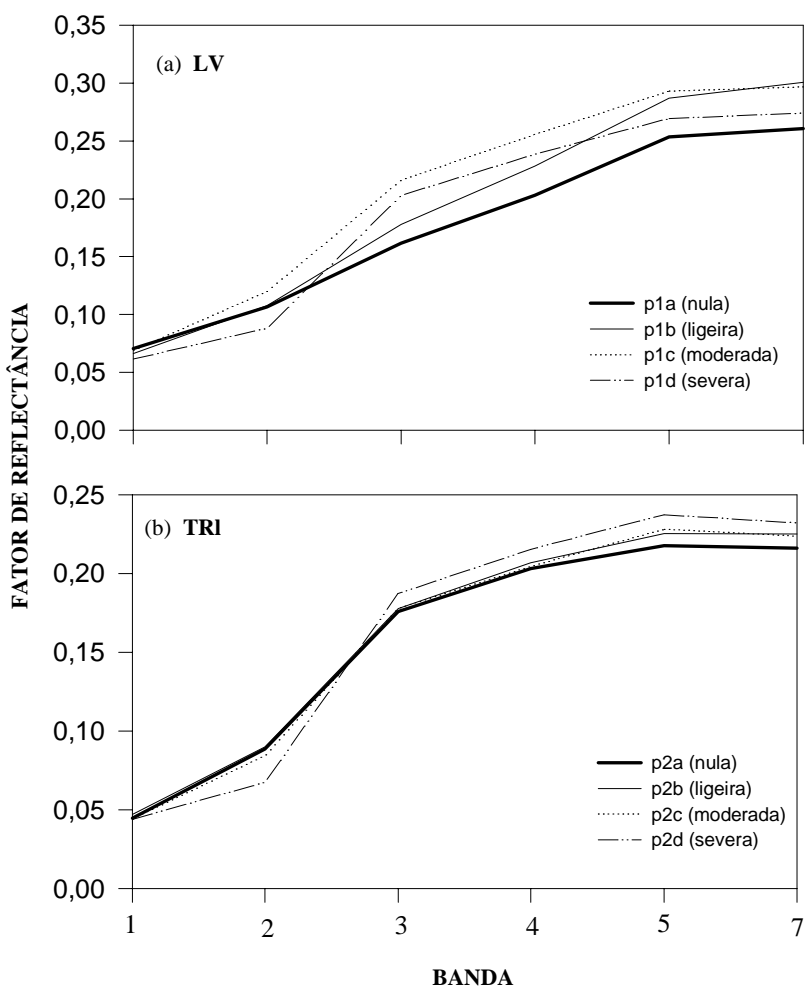

Figura 5. Dados espectrais simulados do TM-LANDSAT, do Latossolo Vermelho-Amarelo LV (a) e Terra Roxa Estruturada latossólica TRI (b) designados por diferentes níveis de erosão. Bandas: 1, 450$520 \mathrm{~nm}$; 2, 520-600 nm; 3, 630-690 nm; 4, 760-900 nm; 5, 1.550-1.750- nm; 7, 2.080-2.350 nm.

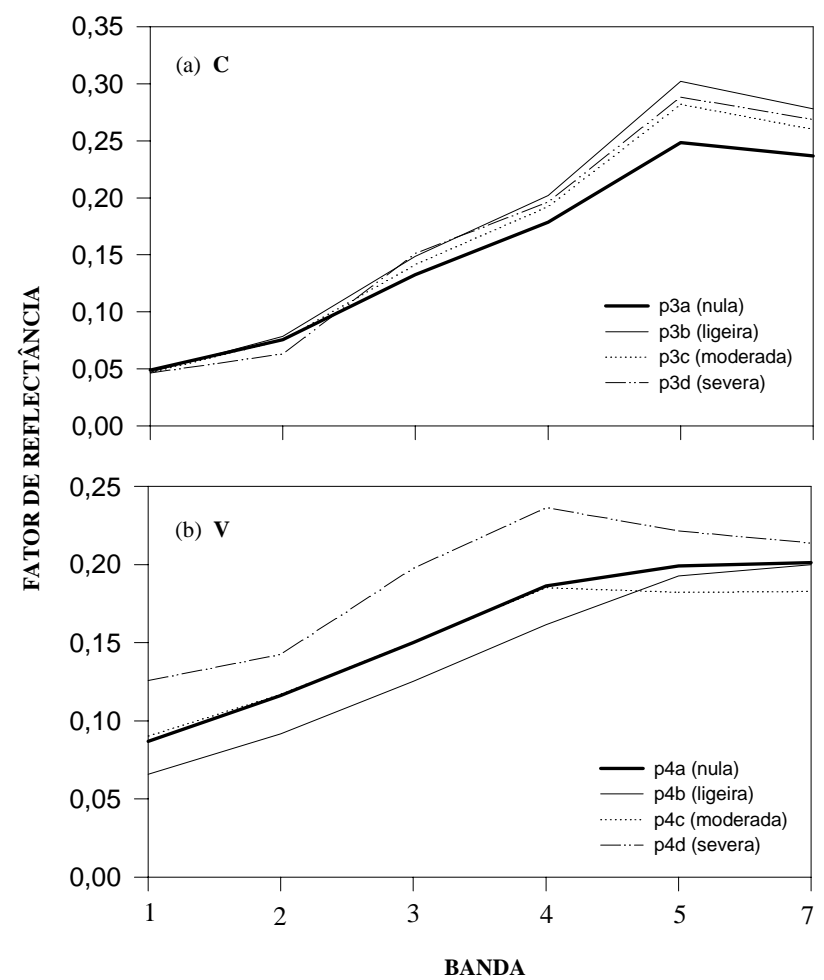

Figura 6. Dados espectrais si mulados do TM-LANDSAT do Cambissolo C (a) e Vertissolo V (b) desi gnados por diferentes níveis de erosão. Bandas: 1, 450-520 nm; 2, 520-600 nm; 3, 630-690 nm; 4, 760-900 nm; 5, 1.550-1.750- $\mathrm{nm} ; 7,2.080-2.350 \mathrm{~nm}$. 
a qual é ascendente para a erosão nula e ligeira e descendente para a erosão moderada e severa.

Os resultados proporcionam a indicação de áreas erodidas por mei o da avaliação da tendência da curva simulada de dados orbitais, concordando com Latz et al. (1984), havendo, entretanto, perda de detal hes em relação aos dados das curvas espectrais de laboratório com melhor resolução espectral. A avaliação da tendência e intensidade das bandas pode-se configurar numa informação complementar no diagnóstico dos níveis de erosão, concordando com Palylyk et al. (1991) e Bober \& MacBride (1996). Entretanto, os dados obtidos neste trabal ho são uma simulação dos gráficos de dados orbitais. Neste caso, não foram considerados os problemas geométricos e atmosféricos que alteram os resultados dos solos quando obtidos ao nível orbital (Guyot et al., 1996). Em função dessas considerações, os dados simulados orbitais deste trabalho são um indicativo das tendências que podem ocorrer nos dados espectrais de solos erodidos, porém sem considerar os fatores citados. Daí, devem ser realizadas novas pesquisas nesta linha, haja vista o potencial que possui para avaliação ambiental.

\section{CONCLUSÕES}

1. Na medida em queaumentou o grau deerosão, ocorreram alterações, principalmente no teor de matéria orgânica, provocando modificações no caráter espectral.

2. Em relação aos dados do sensor terrestre: (a) o nível de erosão nula apresentou menor intensidade de reflectância entre 400 e $2.500 \mathrm{~nm}$ do que os demais níveis, em função do maior teor de matéria orgânica, mostrando-se eficiente nesta discriminação; (b) entre os níveis de erosão ligeira, moderada e severa, a intensidade de reflectância entre 400 e 2.500 nm não se mostrou eficiente na discriminação, com exceção do ocorrido na TRI; c) na medida em que se aumentou o grau de erosão, as bandas de absorção em 1.400, 1.900 e 2.200 nm aumentaram a sua intensidade. As feições de absorção devidas aos óxidos de ferro entre 750 e $1.100 \mathrm{~nm}$ apresentaram maior concavidade nos níveis de erosão mais acentuados; d) a análise conjunta das feições de absorção e intensidade de reflectância mostrou-se eficiente na discriminação de diferentes níveis de erosão.

3. Todos os solos revelaram diferença deintensidade da reflectância de 600 e 2.400 nm, dos solos com erosãonula para a severa. Porém, nem semprehouve relação direta entre o aumento do nível da erosão e o aumento da intensidade de reflectância.

4. Em relação aos dados simulados do TM/ LANDSAT-5, os resultados não permitiram visualizar as bandas de absorção; entretanto, através da intensi dade de reflectância e tendência da curva, foi possível discriminar a erosão nula das demais, principalmente nas bandas 3, 4, 5 e 7.

\section{AGRADE CIMENTO}

À F undação de Amparoà Pesquisa do Estado de São Paulo - FAPE SP, pelo apoio na aquisição do sistema sensor IRIS (Infra Red I ntelligent Spectroradiometer), processo o 1995/6259-6 sem o qual não seria possível a realização desta pesquisa.

\section{LITE RATURA CITADA}

AL-ABBAS, A.H.; SWAIN, P.H. \& BAUMGARDNER, M.F. Relating organic matter and clay content to multispectral radiance of soils. Soil Sci., 114:477-485, 1972.

ALMEIDA, F.F.M.; HASUI,Y.; PONÇANO, W.L.; DANTAS, A.S.L.; CARNEIRO, C.D.R.; MELLO, M.S. \& BIATRICHI, C.A. Mapa geol ógico do estado deSão Paulo. São Paulo, Instituto de Pesquisa Técnica, 1981. 126p. (Monografia, 6)

BAUMGARDNER, M.F.; KRISTOF, S.J .; J OANNSEN, C.J . \& ZACHARY, A.L. Effects of organic matter on the multiespectral properties of soils. Proc. Ind. Acad. Sci., 79:413-422, 1970.

BERTOLINI, D.; LOMBARDI NETO, F. \& DRUGOWICH, M.I. Programa Estadual de Bacias Hidrográficas. Secretaria da Agricultura e Abastecimento do Estado de São Paulo. Campinas: CATI (impresso especial), 1993. 17p.

BERTONI, J . \& LOMBARDI NETO, F. Conservação do solo. São Paulo. Í cone, 1990. 355p.

BOBER, M.L. \& McBRIDE, R.A. Use of digital image analysis and GIS to assess regional compaction risk. Photog. Eng. \& Rem. Sens., 62:1397-1404, 1996.

BRASIL. Ministério da Agricultura. Serviço. Serviço Nacional de Pesquisa Agronômica. Levantamento de reconhecimento de sol os do estado de São Paulo. Rio deJ aneiro, 1960. 634p. (Boletim Técnico, 12)

CAMARGO, O.A.; MONIZ, A.C.; J ORGE, J .A. \& VALADARES, J .M. Métodos de análise química, mineralógica e física de solos do IAC. Campinas, IAC, 1986, 94p. (IAC Boletim Técnico, 106)

CAMARGO, M.N.; KLANT, E.S. \& KAUFMAN, J .H. Classificação de solos usada em levantamentos pedológicos no Brasil. Separata do B. I nf., Sociedade Brasileira de Ciência do Solo, 12:11-33, 1987.

COURAULT, D. \& GIRARD, M.C. Relationships between thesoils composition and their spectral signature. In: ISSS SYMPOSIUM OF THE WORKING GROUP REMOTE SENSING, 5., Budapest, Hungary, 1978. Proceedings. Budapest, 1988. 178-185p.

DEDECEK, R.A. Efeito das perdas e deposições de camadas de solo na produtividade de um latossol o vermel ho escuro do cerrado. R. Bras. Ci. do Solo, 11:323-328, 1987. 
DEMATTÊ, J.A.M. Relações entre dados espectrais e características físicas, químicas e mineralógicas de solos desenvolvidos de rochas eruptivas. Piracicaba, Escola Superior de Agricultura Luiz de Queiróz. 1995. 265p. (Tese de Doutorado)

DEMATTÊ, J .A.M. \& LEITE, A.T.A.B. Efeito da matéria orgânica e ferro nos dados espectrais de solos arenosos e argilosos da região de Bauru, SP. In: SIMPÓSIO DE INICIACCÃO CIENTífICA, 6., Piracicaba, 1998. Resumos. São Paulo, Universidade de São Paulo, 1998. v.1, p.516.

DEMATTÊ, J .A.M.; AMADOR, A. \& NANNI, M.R. Avaliação espectral de amostras de sol os e argilo-minerais em função de diferentes níveis de hidratação. In: SIMPÓSIO BRASILEIRO DE SENSORIAMENTO REMOTO, 9., Santos, 1998. Resumos. Santos, 1998. CD-ROM.

DEMATTÊ, J .L.I .; GARCIA, G.L. \& PROCHNOW, L.I . Variações induzidas de atributos químicos e sua influência na reflectância espectral de três solos do estado do Paraná. R. Bras. Ci. Solo, 3:479-490, 1998.

DEMATTÊ, J .A.M. \& GARCIA, G.J . Alteration of soil properties through a weathering sequence as evaluated by spectral reflectance. Soil Sci. Soc. Am. J ., 63:237-342, 1999.

DEMATTÊ, J .L.I \& \& MARCONI, A. A drenagem na mineralogia dos sol os desenvolvidos de diabásio em Piracicaba (SP). R. Bras. Ci. Solo, 15:1-8, 1991.

EPIPHANIO,J .C.N.; FORMAGGIO,A.R.; VALERIANO, M.M.\& OLIVEIRA, J.B. Comportamento espectral de solos do Estado de São Paulo. São J osé dos Campos, Instituto Nacional de Pesquisas Espaciais, 1992. 131p.

FORMAGGIO, A.R.; EPIPHÂNIO, J.C.; VALERIANO, M.M. \& OLIVEIRA, J .B. Comportamento espectral (450-2450 nm) de solos tropicais de São Paulo. R. Bras. Ci. Solo, 20:467474, 1996.

FRANÇA, G.V. \& DEMATTÊ, J.A.M. Parâmetros da rede de drenagem de solos da região de I racemápolis (SP). An. ESALQ, 47:541-555, 1990.

GROVE, C.I ; HOOK, S.J . \& PAYLOR, E.D. Laboratory reflectance spectra of 160 minerals, 0.4 to 2.5 micrometers. Washington, NASA, National Aeronautics and Space Administration, 1992, 355p. (J et Propulsion Laboratory Publication, febuary 1992)

GUYOT, G.; GU, X.F.; WEISS, M. \& BARET, F. Du signal satellitaire à la réflectance au sol: Problémes direct et inverse. Photo Interp., 2:119-137, 1996.

J ACKSON, M.L. Soil chemical analysis; advanced course. Madison, Wisconsin University, 1969. 895p.

KIEHL, E.J . Fertilizantes orgânicos. São Paulo, Ceres, 1985. 492p.

$L A L, R$. Soil erosion problem on Alfisols in western Nigeria and their control. I badan, Inst. Tropical Agr., 1976. 208p. (Monograph, 1)

LATZ, R.A.; WEISMILLER, G.E.; van SCOTOC \& BAUNGARDNER, M.F. Characteristic variations in spectral reflectance of selected eroded alfisols. Soil Sci. Soc. Am. J ., 45:1130-1134, 1984.

LEMOS, R.C. \& SANTOS, R.D. Manual de descrição e coleta de solo no campo. 3.ed. Campinas, Sociedade Brasileira de Ciência do Solo, 1996. 84p.

LINDBERG, J.D. \& SNYDER, D.G. Diffuse reflectance spectra of several clay minerals. Am. Miner., 57:485-493, 1972.

LOMBARDI NETO, F. Erosão no estado de São Paulo. NOTESALQ, 17: p.1, 1997
MADEIRA NETTO, J .S. Spectral reflectance properties of soils. Photo Interp., 2:59-72, 1996.

MATHEWS, H.L. ; CUNNINGHAM, R.L.; CIPRA, J E. \& WEST, T.R. Aplication of multiespectral remote sensing to soil survey in southeastern Pennsylvania. Soil Sci. Soc. Am. Proc., 37:88-93, 1973.

NICODEMUS, F.E.; RICHMOND, J .C.; HSIA, J .J .; GINS BERG, I.W. \& LIMPERIS, T. Geometrical considerations and nomenclature for reflectance. Washington, D.C., U. S. Department of Commerce, 1977. 52p. (NBS Monograph, 160)

PALYLYK, C.L.; CROWN, P.H. \& SAUCHYN, D.J . Temporal monitoring of agricultural soil erosion risk through integrated Landsat and GIS. In: CANADI AN SYMPOSIUM REMOTE SENSING, 14., Calgary, 1991. Proceedings. Alberta, Calgary, 1991. p.108-111.

PANDOLFO, C.M. Correção da acidez e mel horia da fertilidade do solo. In: MANUAL de uso, manejo e conservação do solo e da água: Projeto de recuperação, conservação e manejo dos recursos naturais em microbacias hidrográficas. 2ed. R., Florianópolis, EPAGRI, 1994. p.149-163.

PAZAR, S.E. Spectral characterization of iron oxide and organic matter in eroded soils. Purdue U niversity, West Lafayette, IN. 1983. (Tese de Mestrado)

PENTEADO, M.M. A bacia de sedimentação de Rio Claro, Estado de São Paulo. Geographica, 5:38-61, 1969.

RAIJ, B. van., J.A. QUAGGIO, H. CANTARELLA, M.E.; FERREIRA, A.S.; LOPES, C.O. \& BATAGLIA. Análise química do solo para fins de fertilidade. Campinas, Fundação Cargill, 1987. 170p.

RANIERI, S.B.L. Avaliação de métodos e escal as detrabal ho para determinação de risco de erosão em bacia hidrográfica utilizando sistema de informações geográficas (SIG). São Carlos, Universidade de São Paulo, 1996. 128p. (Tese de Mestrado)

SEUBERT, C.E.; BAUMGARDNER, M.R.; WEISMILLER, R.A. \& KIRSCHNER, F.R. Mapping and estimating areal extent of severely eroded soils of selected sites in northern Indiana. In: MACHINE PROCESSING OF REMOTELY SENSED DATA SYMP. West Lafayette, Purdue University, 1979. 170p.

SPAROVEK, G.; TERAMOTO, E.R., TORETA, D.M.; ROCHELES, T.C.A. \& SHAYER, E.P.M. Erosão simulada e a produtividade da cultura do milho. Rev. Bras. Ci. do Solo, , 15:363-369, 1991.

SPAROVEK, G.; van LIER, Q.J .; ALOISI, R.R. \& TORRADO, P.V. Previsão do rendimento de uma cultura em solos de Piracicaba em função da erosão. R. Bras. Ci. Solo, 17:465470, 1993.

STONER, E.R.; BAUMGARDNER, M.R.; BIEHL, L.L. \& ROBINSON, B.F. Atlas of soil reflectance properties. West Lafayette, Purdue University, 1980. 75p.

STONER, E.R. \& BAUMGARDNER, M.F. Characteristic variations in reflectance of surface soils. Soil Sci. Soc. Am. J ., 45:1161-1165, 1981.

VITORELLO, I. \& GALVÃO, L.S. Spectral properties of geologic materials in the 400 to $2.500 \mathrm{~nm}$ range: review for applications to mineral exploration and lithologic mapping. Photo Interp., 2:77-99, 1996.

WEISMILLER, R.A. \& KAMINSKY, S.A. Aplication of remotesensing technology to soil survey reseach. J. Soil Water Conser., 33:287-289, 1978. 